\title{
Patent ductus arteriosus with persistent pulmonary artery hypertension after transcatheter closure
}

This article was published in the following Dove Press journal:

Therapeutics and Clinical Risk Management

3 November 2016

Number of times this article has been viewed

\author{
Jianqi Feng ${ }^{1,2}$ \\ Xiangqing Kong' \\ Yanhui Sheng' \\ Rong Yang' \\ 'Department of Cardiology, the \\ First Affiliated Hospital of Nanjing \\ Medical University, Nanjing, Jiangsu, \\ ${ }^{2}$ Department of Cardiology, the \\ Second Affiliated Hospital of XuZhou \\ Medical University, XuZhou, Jiangsu, \\ People's Republic of China
}

Objectives: To observe the change in pulmonary artery systolic pressure (PASP) of patients with persistent pulmonary arterial hypertension (PAH) after patent ductus arteriosus (PDA) occlusion. Background: After occlusion of PDA in patients with PAH, some patients still tend to suffer from persistent $\mathrm{PAH}$.

Methods: A chest X-ray, an electrocardiogram, and an echocardiogram were performed on nine patients at 24 hours, 1 and 6 months, and 1 year serially.

Results: There was a significant fall $(P<0.05)$ in mean PASP after occlusion (to $59.3 \pm 12.7$ $\mathrm{mmHg}$ ). However, the aortic pressure and systemic arterial oxygen saturation changed slightly $(P>0.05)$. During the follow up, there was a further fall in the PASP in five patients (No 1, 5, 6,7 , and 8). Four patients (No 2, 3, 4, and 8) showed the evidence of worsening PAH and were treated with sildenafil. Patient 2 died from acute right heart failure after a period of 11 months from the time of transcatheter closure, triggered by pulmonary infection.

Conclusion: Some patients with borderline hemodynamic data with PDA and PAH can deteriorate or keep sustained PAH after PDA closure. The treatment of permanent closure to these patients must be cautious.

Keywords: patent ductus arteriosus (PDA), transcatheter closure (TCC), pulmonary artery hypertension, follow-up

\section{Introduction}

Patent ductus arteriosus (PDA) is one of the most common congenital heart defects, accounting for $5 \%-10 \%$ of all congenital heart disease in infants. ${ }^{1}$ Transcatheter closure (TCC) PDA was first performed in $1971 .^{2}$ With the progress of technique and material, TCC of PDA with various occluders has been well established and become the treatment of choice for the majority of patients with this condition. ${ }^{3-10}$ However, whether to attempt TCC of PDA in patients with severe pulmonary arterial hypertension $(\mathrm{PAH})$ remains a challenging clinical problem, as there is not much information on the immediate and long-term effects of TCC of PDA in patients who have PAH, especially those with persistent PAH after occlusion.

\section{Materials and methods}

\section{Patients}

From July 2006 to January 2011, nine patients with clinical and echocardiographic findings of a PDA and severe pulmonary hypertension underwent TCC with the Amplatzer duct occluder (ADO, AGA Medical Corporation, Golden Valley, MN, USA). Pulmonary hypertension maintained after occlusion. 
Their mean age was $24.2 \pm 8.2$ years (range $16-42$ years) and their median body weight was $53.6 \pm 7.8 \mathrm{~kg}$ (range 46-71 kg). The study was approved by the Ethics Committee of Nanjing Medical University. Written informed consents were obtained from all patients.

\section{Interventional procedure}

The technique of TCC of PDA using the ADO was similar to that described by Masura et al. ${ }^{11}$ After a complete hemodynamic evaluation and descending aortogram in the lateral or right anterior oblique view, trial occlusion with the ADO (the size of the occlusion device we chose was 4-6 mm larger than the narrowest size of the PDA) was performed for 30 minutes to record the change in hemodynamic and clinical data. If the pulmonary arterial pressure fell or did not increase, the aortic pressure did not decrease, and the signs and symptoms did not worsen, then the PDA occluder was released. A repeat descending aortogram excluded a moderate-to-large residual left-to-right shunt. Otherwise, the occluding device was retracted into the delivery sheath. Prophylactic antibiotics were routinely given after the procedure for 3 days. All the patients returned home after 2 days of observation in the cardiac ward.

\section{Follow-up}

A chest X-ray, an electrocardiogram, and an echocardiogram were performed on all the patients at 24 hours, 1 and 6 months, and 1 year serially.

\section{Statistics}

The results were analyzed using SPSS 13.0 (SPSS Inc., Chicago, IL, USA) and expressed as mean (standard deviation), with confidence intervals where applicable. Preocclusion and postocclusion data were compared using paired-samples $t$-tests. A probability value of $P<0.05$ was considered significant.

\section{Results}

The clinical and hemodynamic data before and after occlusion of nine patients are shown in Tables 1 and 2. The PDA size was 8.9 (3.0) $\mathrm{mm}$ (range 5-15 mm). The mean ADO diameter was $14.8(3.0) \mathrm{mm}(11-20 \mathrm{~mm})$. The ratio of pulmonary blood flow to systemic flow (Qp/Qs) was $2.2(0.7)$ (range 1.7-3.94). The mean pulmonary vascular resistance (PVR) at baseline was 6.4 (2.8) Woods units (range 2.7-12.6 Woods). The mean pulmonary artery systolic pressure (PASP) and aortic systolic pressure at baseline were 106.7 (21.5) $\mathrm{mmHg}$ (range 78-140 $\mathrm{mmHg}$ ) and 137.1 (8.1) $\mathrm{mmHg}$ (range $127-147 \mathrm{mmHg}$ ), respectively. There was a significant fall $(P<0.05)$ in mean PASP after occlusion (to $59.3 \pm 12.7 \mathrm{mmHg}$ ).
Table I Clinical data of patients who underwent PDA occlusion $(n=9)$

\begin{tabular}{|c|c|c|c|c|c|}
\hline $\begin{array}{l}\text { Patient } \\
\text { no }\end{array}$ & Sex & $\begin{array}{l}\text { Age } \\
\text { (years) }\end{array}$ & $\begin{array}{l}\text { Weight } \\
\text { (kg) }\end{array}$ & $\begin{array}{l}\text { PDA diameter } \\
(\mathrm{mm})\end{array}$ & $\begin{array}{l}\text { Device } \\
\text { size }(\mathrm{mm})\end{array}$ \\
\hline 1 & $\mathrm{~F}$ & 19 & 52 & 5 & II \\
\hline 2 & $\mathrm{~F}$ & 16 & 46 & 10 & 16 \\
\hline 3 & $F$ & 28 & 61 & 15 & 20 \\
\hline 4 & $\mathrm{~F}$ & 20 & 48 & II & 18 \\
\hline 5 & $F$ & 42 & 50 & 10 & 16 \\
\hline 6 & $F$ & 31 & 53 & 8 & 14 \\
\hline 7 & $M$ & 21 & 71 & 6 & 12 \\
\hline 8 & $\mathrm{~F}$ & 18 & 52 & 8 & 14 \\
\hline 9 & $F$ & 23 & 49 & 7 & 12 \\
\hline \multicolumn{2}{|c|}{ Total $(n=9)$} & $24.2 \pm 8.2^{*}$ & $53.6 \pm 7.8 *$ & $8.9 \pm 3.0 *$ & $14.8 \pm 3.0^{*}$ \\
\hline
\end{tabular}

Note: *Data presented as mean \pm standard deviation.

Abbreviation: PDA, patent ductus arteriosus.

However, the change in aortic pressure and systemic arterial oxygen saturation $\left(\mathrm{SaO}_{2}\right)$ was insignificant $(P>0.05)$.

The mean follow-up time was 3.6 years (range 0.9-7 years). During the follow up, PASP was obtained from echo/Doppler study. There was a further fall of PASP in five patients (No 1, 5, 6, 7, and 8). Four patients (No 2, 3, 4 , and 8 ) showed evidence of worsening of PAH and were treated with sildenafil. Patient 2 died from acute right heart failure after a period of 11 months from the time of TCC, which was triggered by a pulmonary infection (Table 3 , Figures 1 and 2).

\section{Discussion}

TCC is now widely accepted as the first-choice treatment of PDA. The increasing experience allows PDA patients with $\mathrm{PAH}$ to be evaluated for transcatheter device occlusion. The findings of the present study indicated that TCC of PDA in patients with PAH is feasible, effective, and safe, even in severely symptomatic patients. ${ }^{12-17}$ However, a small percentage of patients with borderline hemodynamic data with PDA and PAH can deteriorate after PDA closure due to non-regression of pulmonary hypertension, progressive pulmonary vascular disease, and right heart failure. Their natural history is similar to idiopathic PAH. In our study, the PASP of nine patients decreased by $>20 \%$ immediately after occlusion. During the follow-up of these patients, PASP of five patients decreased further and worsened in the remaining four patients. The PASP of all nine patients did return back to normal. For patients 1 and 7, the PDA diameter was only 5 or $6 \mathrm{~mm}$. According to the clinical classification of pulmonary hypertension, ${ }^{18}$ this is generally classified as PAH associated with small defects. But we were unable to differentiate whether it was PDA with idiopathic PAH.

Whether to attempt TCC of PDA in patients with severe PAH remains a challenging clinical problem. In this 


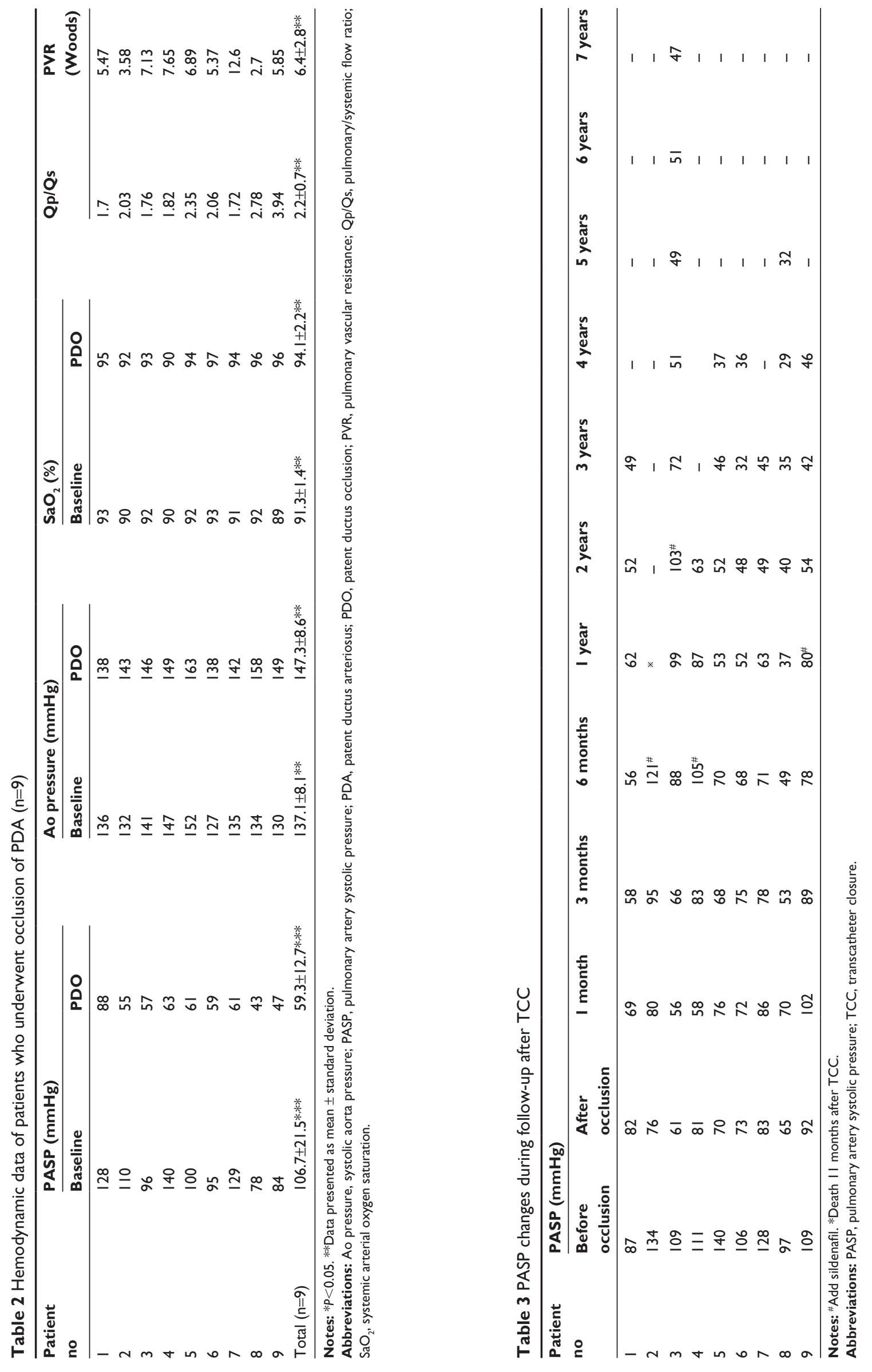




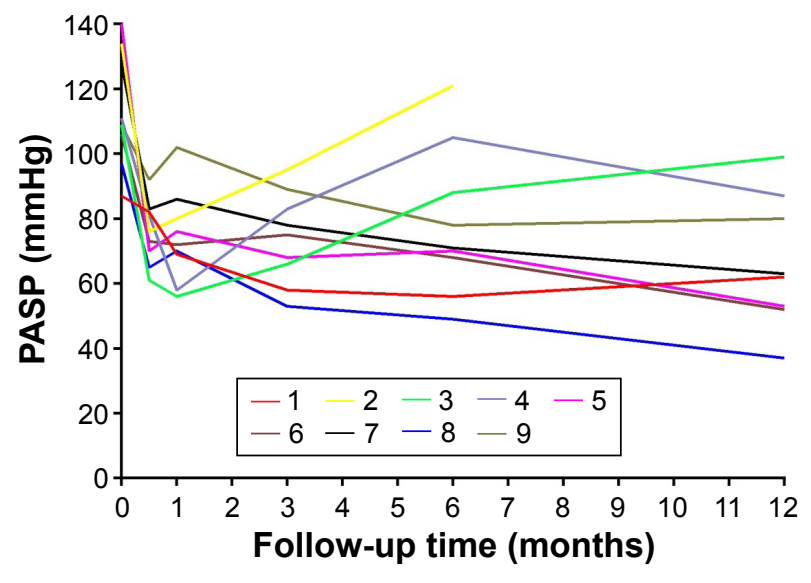

Figure I PASP changes within I year after TCC.

Abbreviations: PASP, pulmonary artery systolic pressure; TCC, transcatheter closure.

condition, the most important determinant of management and prognosis is whether the severe PAH is reversible. Clinical examination is used to evaluate the reversibility of severe PAH. However, taking a decision to intervene is difficult if the clinical examinations are equivocal and there are some limitations for calculating PVR in PDA. A multicenter study by Balzar et al concluded that the use of vasodilators, including inhaled nitric oxide, has limited utility in deciding operability. ${ }^{19}$ Contrary to the popular belief, a recent study showed that preoperative hemodynamic information does not correlate with postoperative outcome for various reasons. ${ }^{20}$

Trial occlusion of PDA with device has been in use to decide on the contribution of left to right shunt and PVR to PAH. ${ }^{15,19,21-23}$ The criteria that we followed were as follows: 1) a fall in the pulmonary artery pressure or no elevation; 2) no decrease in the aortic pressure and $\mathrm{SaO}_{2}$; and 3) no worsening of signs and symptoms. If all the criteria were satisfied, we considered the PAH to be reversible. Otherwise,

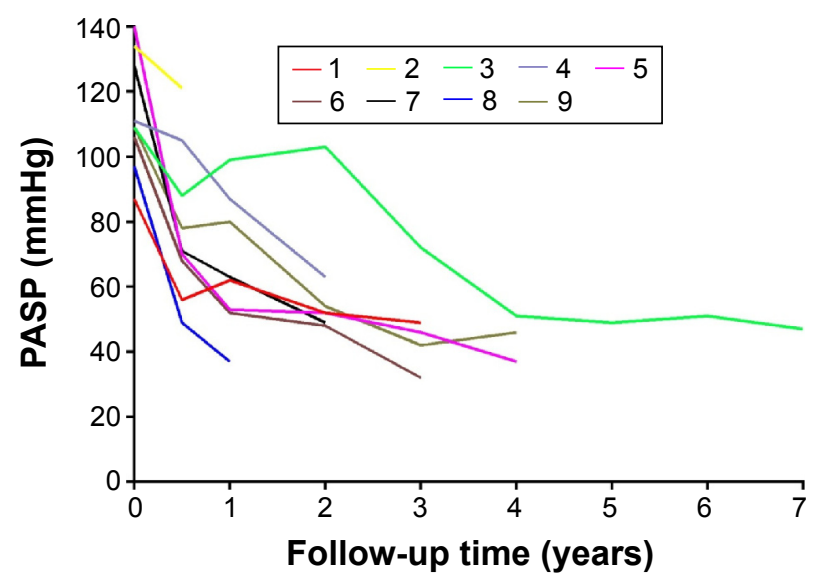

Figure 2 PASP changes over I year after TCC.

Abbreviations: PASP, pulmonary artery systolic pressure; TCC, transcatheter closure. it was considered to be irreversible PAH and occlusion was abandoned. This is a reliable test to exclude patients with borderline hemodynamic data from undergoing device closure. ${ }^{15,21,24}$

Sildenafil has been shown to improve exercise capacity, oxygen saturations, cardiopulmonary hemodynamics, and World Health Organization function class in patients with $\mathrm{PAH}$, including $\mathrm{PAH}$ in patients with congenital heart disease having PAH. ${ }^{25-29}$ Longer-term studies have suggested sustained benefits. A larger randomized trial of 278 patients, including 7\% with Eisenmenger syndrome, showed significant benefit after 19 months. ${ }^{25}$ In our study, after being treated with sildenafil, there was a decrease in the PASP of patients with PDA after closure.

\section{Study limitations}

There are two main limitations in our study. First, the major limitation of the study was the small sample size which limited its power. Second, during the follow-up, pulmonary arterial pressure was only evaluated by ultrasound. No patients underwent catheterization again.

\section{Conclusion}

TCC for PDA with severe PAH is currently the preferred method. However, some patients with borderline hemodynamic data with PDA and PAH can deteriorate or keep sustained PAH after PDA closure, although PAP would decrease by $>20 \%$ immediately after trial occlusion. In such patients, the treatment of permanent closure must be performed with caution.

\section{Disclosure}

The authors report no conflicts of interest in this work.

\section{References}

1. Schneider DJ, Moore JW. Patent ductus arteriosus. Circulation. 2006; 114(17):1873-1882.

2. Portsmann W, Wierny L, Warnke H, Gerstberger G, Romaniuk PA. Catheter closure of patent ductus arteriosus, 62 cases treated without thoracotomy. Radiol Clin North Am. 1971;9(2):203-218.

3. Baumgartner H, Bonhoeffer P, De Groot NM, et al. Guidelines for the management of grown-up congenital heart disease (new version 2010): the task force on the management of grown-up congenital heart disease of the European society of cardiology (ESC), endorsed by the association for European paediatric cardiology (AEPC). Eur Heart J. 2010;31(23):2915-2957.

4. Rao PS, Kim SH, Choi JY, et al. Follow-up of transvenous occlusion of patent ductus arteriosus with the buttoned device. J Am Coll Cardiol. 1999;33(3):820-826.

5. Hijazi ZM, Geggel RL. Transcatheter closure of large patent ductus arteriosus ( $\geq 4 \mathrm{~mm}$ ) with multiple Gianturco coils: immediate and midterm results. Heart. 1996;76(6):536-540.

6. Uzun O, Hancock S, Parsons JM, Dickinson DF, Gibbs JL. Transcatheter occlusion of the atrial duct with Cook detachable coil: early experience. Heart. 1996;76(6):269-273. 
7. Hijazi ZM, Geggel RL. Results of anterograde transcatheter closure of patent ductus arteriosus using single or multiple Gianturco coils. J Am Coll Cardiol. 1994;74(9):925-929.

8. Verin VE, Saveliev SV, Kolody SM, Prokubovski VI. Results of transcatheter closure of the patent ductus arteriosus with the Botalloocluder. J Am Coll Cardiol. 1993;22(5):1509-1514.

9. Hosking MCK, Benson LN, Musewe N, Dyck JD, Freedom RM. Transcatheter occlusion of the persistently patent ductus arteriosus: forty-month follow-up and prevalence of residual shunting. Circulation 1991;84(6):2313-2317.

10. Rashkind WJ, Mullins CE, Helenbrand WE, Tait MA. Non-surgical closure of patent ductus arteriosus: clinical application of the Rashkind PDA occluder system. Circulation. 1987;75(3):583-592.

11. Masura J, Kevin P, Thanopoulos B, et al. Catheter closure of moderate to large-sized patent ductus arteriosus using the new Amplatzer duct occluder: immediate and short-term results. J Am Coll Cardiol. 1998; 31(4):878-882.

12. Zhang CJ, Huang YG, Huang XS, et al. Transcatheter closure of large patent ductus arteriosus with severe pulmonary arterial hypertension in adults: immediate and two-year follow-up results. Chinese. Med J. 2012;125(21):3844-3850.

13. Tharakan J, Venkateshwaran S. Large patent ductus arteriosus: to close or not to close. Ann Pediatr Cardiol. 2012;5(2):141-144.

14. Bhalgat PS, Pinto R, Dalvi BV. Transcatheter closure of large patent ductus arteriosus with severe pulmonary arterial hypertension: short and intermediate term results. Ann Pediatr Cardiol. 2012;5(2): 135-140.

15. Yan $\mathrm{C}$, Zhao S, Jiang S, et al. Transcatheter closure of patent ductus arteriosus with severe pulmonary arterial hypertension in adults. Heart. 2007;93(4):514-518.

16. Ji Q, Feng J, Mei Y, et al. Transcatheter closure of adult patent ductus arteriosus with severe pulmonary hypertension. Hypertens Res. 2008;31(11):1997-2002.

17. Yu ML, Huang XM, Wang JF, Qin YW, Zhao XX, Zheng X. Safety and efficacy of transcatheter closure of large patent ductus arteriosus in adults with a self-expandable occluder. Heart Vessels. 2009;24(6): 440-445.

18. Simonneau G, Robbins IM, Beghetti M, et al. Updated clinical classification of pulmonary hypertension. J Am Coll Cardiol. 2009; 54(1 Suppl):S43-S54.
19. Balzer DT, Kort HW, Day RW, et al. Inhaled Nitric Oxide as a Preoperative Test (INOP Test I): the INOP Test Study Group. Circulation. 2002;106(12 Suppl 1):176-181.

20. Kannan BR, Sivasankaran S, Tharakan JA, et al. Long term outcome of patients operated for large ventricular septal defects with increased pulmonary vascular resistance. Indian Heart J. 2003;55(2):161-166.

21. Yang SW, Zhou YJ, Hu DY, et al. Feasibility and safety of transcatheter intervention for complex patent ductus arteriosus. Angiology. 2010;61(4):372-376.

22. Thanopoulos BD, Tsaousis GS, Djukic M, AL Hakim F, Eleftherakis NG, Simeunovic SD. Transcatheter closure of high pulmonary pressure persistent ductus arteriosus with Amplatzer muscular ventricular septal defect occluder. Heart. 2002;87(3):260-263.

23. Roy A, Juneja R, Saxena A. Use of Amplatzer duct occluder to close severely hypertensive ducts: utility of transient balloon occlusion. Indian Heart J. 2005;57(4):332-336.

24. Viswanathan S, Kumar RK. Assessment of operability of congenital cardiac shunts with increased pulmonary vascular resistance. Catheter Cardiovasc Interv. 2008;71(5):665-670.

25. Galiè N, Ghofrani HA, Torbicki A, et al. Sildenafil Use in pulmonary arterial hypertension (SUPER) study group. sildenafil citrate therapy for pulmonary arterial hypertension. $N \mathrm{Engl} \mathrm{J} \mathrm{Med}$. 2005;353(20):2148-2157.

26. Chau EM, Fan KY, Chow WH. Effects of chronic sildenafil in patients with Eisenmenger syndrome versus idiopathic pulmonary arterial hypertension. Int J Cardiol. 2007;120(3):301-305.

27. Singh TP, Rohit M, Grover A, Malhotra S, Vijayvergiya R. A randomized, placebocontrolled, double-blind, crossover study to evaluate the efficacy of oral sildenafil therapy in severe pulmonary artery hypertension. Am Heart J. 2006;151(4):851, e1-e5.

28. Garg N, Sharma MK, Sinha N. Role of oral sildenafil in severe pulmonary arterial hypertension: clinical efficacy and dose response relationship. Int J Cardiol. 2007;120(3):306-313.

29. Tay EL, Papaphylactou M, Diller GP, et al. Quality of life and functional capacity can be improved in patients with Eisenmenger syndrome with oral sildenafil therapy. Int J Cardiol. 2011;149(3):372-376.
Therapeutics and Clinical Risk Management

\section{Publish your work in this journal}

Therapeutics and Clinical Risk Management is an international, peerreviewed journal of clinical therapeutics and risk management, focusing on concise rapid reporting of clinical studies in all therapeutic areas, outcomes, safety, and programs for the effective, safe, and sustained use of medicines. This journal is indexed on PubMed Central, CAS,

\section{Dovepress}

EMBase, Scopus and the Elsevier Bibliographic databases. The manuscript management system is completely online and includes a very quick and fair peer-review system, which is all easy to use. Visit http://www.dovepress.com/testimonials.php to read real quotes from published authors. 